\title{
Fashion, Market and Materiality Along the Seams of Clothing
}

\author{
By Therése Andersson
}

\begin{abstract}
Andy: [seeing Nigel holding an exclusive gown] I love that! Will that fit me? Nigel: A little Crisco and some fishing wire and we'll be in business.
\end{abstract}

The Devil Wears Prada (2006)

The aim of the 'Fashion, Market and Materiality' section is to let fashion / dress / textile scholars deal with the topic from their own particular theoretical perspective and subject of interest. The study of clothing, costume and fabrics is, as such, a field, which crosses established boundaries between academic disciplines. There are no claims whatsoever of giving an account of the entire field of fashion studies, or of dealing with every subject matter possible within the sphere. Instead, this section brings together a range of scholarly approaches and methodological frameworks, and by compiling these articles the interconnections between production and consumption of fashion and dress are acknowledged. As Joanne Entwistle argues: the relationships between different agencies, institutions, individuals and practices ought to be considered for a better understanding of fashion and dress (Entwistle 2000:3).

This article begins with a quote drawn from the filmic comedy-drama The Devil Wears Prada (David Frankel, 2006). It captures Andy's (Anne Hathaway) naive hope of squeezing into a dazzling, too expensive, size zero designer garment, only to be undeceived by Nigel's (Stanley Tucci) sarcastic remark. Aside from sarcasm, Nigel's comment reflects the opinion that high fashion is only available for a select few: determined by income, social status, and body type. Hence, the concept of high fashion tends to become abstract and unattainable, but at the same time fashion provides, as Entwistle puts it: 'the "raw material" of daily dress', pointing to the transformation of fashion into dress by individuals (Entwistle 2000: 1ff.). In this section, the concepts of both fashion and dress will be considered, applied, and combined. Furthermore, the quote from the film articulates the connecting threads (fishing wire) between the articles of this section: the intricate business of appearance, fit and materiality. As clothing is lived and experienced, the encounters with fashion in everyday life involve not only the apparent questions of personal taste and aesthetics, but relate to more diffuse ideas concerning our own body and identity.

Clothing in the most unproblematic sense is used as protection against the elements and, basically, garments embellish the body, conceal the body, or 
display the body. In the cultural and social contexts of everyday life however, conventions of dress transform bodies into recognizable and meaningful entities acceptable within specific contexts (Entwistle 2001: 33). Dressing the body consequently concerns dressing the social self, trying out different looks, and, furthermore, different identities. Similarly to the use of dress to hide or reveal the body, fashion can be deployed to conceal or display an identity. By dressing in a particular way something is said about the individual: about gender, age, social status, and in certain cases referring directly to a subcultural affiliation, for instance regarding music or sport. To dress fashionably and/or in accordance with the codes of particular affiliations is simultaneously to stand out and to stick with the group and as Elizabeth Wilson puts it: 'to lay claim to the exclusive and to follow the herd' (Wilson 2003: 6), pointing to a contradictory mode of fashion.

As the body is a site for identity, clothing has a key function in a non-verbal communication process where appearances are negotiated. For instance, Judy Attfield calls attention to clothing and textiles as having 'a particular intimate quality because they lie next to the skin and inhabit the spaces of private life helping to negotiate the inner self with the outside world' (Attfield 2000: 121). The materiality of garments, the cuts and compositions, are regarded as signs in communication: as expressions of symbolic meanings whether it is about football strips, branding the nation, or interpretations of characters in a screenplay. Clothing and textile also have the quality to evoke and mediate emotions (Attfield 2000: 121), for instance the denotations of mourning attire are grief and loss. But, in a more complex sense, garments have in their immediacy an influence on how the wearer feels about herself; for instance, clothes could make one feel totally confident or totally wrong. From this angle emerges the interplay between fashion and emotions: the affect of materiality traces back to opinions and experiences of one's own body.

Hence, as Yuniya Kawamura points out, an understanding of fashion also involves 'an analysis of consumers who adopt fashion and their consumption behaviour because the consumers participate indirectly in the production of fashion' (Kawamura 2005:89). For instance, the practice of shopping is an immediate engagement between consumers and fashion, either as an experience visiting a store on location, browsing and touching actual garments, and taking advantage of the possibility to try on the favoured attires and decide if they fit or not; or visiting an on-line store, browsing through static images of garments and trying to estimate the fit before purchase. Without the act of reception, as Kawamura argues, the cultural production of fashion is not complete (Ibid 2005:89). Consumption behaviour and experiences of clothes due to body type are further discussed in 'Materialised Ideals: Sizes and Beauty' by Ingun Grimstad Klepp, Kirsi Laitala and Benedicte Hauge. Klepp, Laitala and Hauge have studied today's sizing systems. Their research was based on a web survey of Nordic consumers; complemented with in-depth interviews, market analysis of clothing 
sizes, and in-store trouser size measurements. At present the clothing industry is based on systems where clothes are made in ready-to-wear sizes and meant to fit most people. However, as previous studies have pointed out, many consumers are discontent with the use of these sizing systems; quite simply size designations are not accurate enough. In their study Klepp, Laitala and Hauge identify which consumer groups fall within these designations, and which do not. The results of this investigation of consumer behaviour indicates that a higher proportion of the consumers who have a body shape that diverges from the existing beauty ideals express discontentment with the sizing systems and the poor selection available.

Shopping and fashion retail as such opens the doors of visual as well as spatial accessibility to designer garments, and Christopher Breward describes the store as a significant staging post in 'the trail of the product from design and manufacture to the intimate realm of the wearer'. (Breward 2003: 143). In her article 'Retail and Fashion - A Happy Marriage? The Making of a Fashion Industry Research Design', Cecilia Fredriksson sets out to analyse the Swedish fashion business as a narrative of different social and cultural processes. She focuses on the narratives surrounding fashion storeowner Helena Svensson and fashion designer Filippa Knutsson. These are used to examine the symbolic status and oppositions between the creative entrepreneurship of fashion retail; opening a store of one's own; fashion design; and starting an own-name line of clothing. In the cases of both Svensson and Knutsson, fashion is presented as a passion, the realisation of a dream come true, and success in a tough business. But Fredriksson points out that the road to success differs, depending on whether you have to work and succeed on your own like Svensson, or if you are born into an entrepreneurial family with established connections as was the case with Knutsson. Fredriksson argues that: 'The inherent paradoxes between design, fashion and retail have to be analysed as different logics within different systems. These cultural systems produce and reproduce different stereotype identities that the fashion industry has to manage.'

Stores offer, as mentioned above, experiences of fashion staging in everyday life; nevertheless, the showcasing of fashion is inevitably associated with the spectacle of the fashion weeks and the runway shows in major cities. As media saturated, high profile events, the concepts of designer collection are broadcasted, in conjunction with a wider promotion of the culture and creative economy of the host cities (Breward 2006: ix). The spatial point of departure for the article 'Catwalking the Nation: challenges and possibilities in the case of the Danish fashion industry', by Marie Riegels Melchior, is Copenhagen Fashion Week 2010. Due to the event a large runway - named 'The World's Greatest Catwalk' - was built for showcasing Danish fashion design. Riegels Melchior understands the case of 'The World's Greatest Catwalk' as a materialization of, and culmination of, several years of joint industry engagement in Denmark aimed at strengthening the Danish fashion industry, as well as an opportunity for the Danish Government to invest in nation-branding. In the context of Danish fashion Riegels Melchior 
then examines the mobilization of the nation for fashion, based on how the relationship between fashion and nation unfolds in contemporary fashion research and in practice, drawing attention to a current emphasis on national identity in fashion design as a mark of difference and collective identity.

Issues of national identity are also implied in the discussion of competitive sport and high performance textiles, as international success in championships clearly belongs to the arena of nation branding. The difference between gold and bronze medals could, in the case of swimming, be the reduction of friction drag by just 4 per cent (Clarke \& O'Mahony 2005: 144). In her article 'The Fastskin Revolution: From Human Fish to Swimming Androids' Jennifer Craik follows the debate during the last decade surrounding the fastskin swimsuit - well known from the Sydney 2000 Olympic Games - starting from the dichotomy in perception, as to whether the body suit was a performance altering apparatus or a swimming costume. The story of fastskin swimsuits, Craik argues, reflects some of the challenges facing the impacts of technology in postmodern culture. As large investments have been made in researching performance enhancing techniques and equipment, competitive sport has been placed at the cutting edge of new technologies that have "produced new fabrics and textiles based on state-of-the-art knowledge about ergonomics, aerodynamics, anthropometry, biomechanics, and other specialisations'. Craik asserts that new kinds of sports clothing such as the fastskin has been one product of this research and that this has transformed the nature of sportswear for competition, recreation and as casual wear. The article then deals with different dimensions of the image of the sport of swimming, as it has been 're-mapped as a technical artefact and sci-fi spectacle based on a radically transformed concept of the swimming body as a material object that has implications for the ideal of the fashionable body'.

As pointed out above, many of the developments that have been made in technical materials - such as neoprene - were originally designed for sports. Textile companies continue to invest in research and development; marketing fabrics that combine an attractive look with good feel, where design and tactility are integrated with properties designated to protect the wearer from the elements and which are beneficial to health and well-being (Clarke \& O'Mahony 2005: 108f.). Tactile experiences of sports clothing are also discussed by Viveka Berggren Torell in her article 'As Fast as Possible Rather than well Protected: Experiences of Football Clothes'. Maurice Merleau-Ponty's phenomenological view: 'that we "take in" the world and experience ourselves, as subjects through our bodies', constitute the theoretical point of departure. Berggren Torell has interviewed Swedish football players - in both men's and women's teams coaches, kit men, buyers of clothes, and sport directors, about their perceptions and experiences of football clothes. Since the body is both a feeling and knowing entity, Berggren Torell holds clothes as "components of body techniques, facilitating or restraining body movements in a material way, but also as creators 
of senses like lightness and security; in both ways influencing the knowledge in action that football playing is'. The content of the interviews is further discussed in relation to health issues concerning both bodily and psychological well-being.

Tactile experiences of dress also play a part in 'Costume Cinema and Materiality: Telling the Story of Marie Antoinette through Dress' by Therése Andersson. Instead of examining how certain films have influenced the fashion scene, or studying film stars as fashion icons, or considering how dress operates in relation to stardom (Moseley 2005: 1ff.), Andersson experiments with a materiality based approach for analysing film narratives through costumes. Sofia Coppola's film Marie Antoinette (2006) serves as the empirical starting point and Andersson argues that costumes, on a symbolic level, work as agents: focusing on the interdependence between costume and interpretations of the screenplay's main character. Crystallizing costume as a significant feature for reading the movie, a theoretical notion of costumes and materiality is explored. This notion is further developed in relation to stylistics constituted as emotions materialised in costume. As costumes are the main object for analysis, the discussion immediately centres on costumes created by professional costume designers for the two-dimensional format of the film frame; costumes made for the moment: for a specific narrative and aesthetic expression.

The different takes on fashion and dress in these articles, the varying topics analysed and the research questions discussed, demonstrate the multi-faceted subject of fashion and materiality; the continuous interrelationship between the global and the local, between the exclusive and the mundane, between high fashion and everyday practices of dress. And, as the opening quotation from The Devil Wears Prada illustrates, the sometimes all too familiar dilemma: adoration of a fabulous dress, and the harsh knowledge of non-fit. Because clothing is lived and experienced it generates feelings and emotions in the wearer. As a consequence the contradictory mode of fashion tends to bring about ambivalence in responses to dress:

Fashion is ambivalent - for when we dress we wear inscribed upon our bodies the often obscure relationship of art, personal psychology and the social order. And this is why we remain endlessly troubled by fashion - drawn to it, yet repelled by fear of what we might find hidden within its purposes, masked by the enigma of its Mona Lisa smile. (Wilson 2003: 247)

Do you dare to open the doors and step into the wardrobe?

Therése Andersson is currently employed at the Department of History, Stockholm University. Her doctoral thesis in Cinema Studies is entitled Beauty Box: Film Stars and Beauty Culture in Early 20th Century Sweden (2006). Andersson is currently working on the research project Velcro, Button, and Zip: Power and Materiality during Styling and Dressing, funded by the Bank of Sweden Tercentenary Foundation. E-mail: therese.andersson@ historia.su.se 


\section{References}

Attfield, Judy (2000): Wild Things: The Material Culture of Everyday Life, Oxford \& New York: Berg.

Breward, Christopher (2003): Fashion, Oxford: Oxford University Press. (2006): Fashion's World Cities, Oxford \& New York: Berg.

Clarke, Sarah E. Braddock \& O'Mahony, Marie (2005): Techno Textiles 2: Revolutionary Fabrics for Fashion and Design, Thames \& Hudson: London.

Entwistle, Joanne (2000): The Fashioned Body: Fashion, Dress and Modern Social Theory, Cambridge: Polity Press.

Entwistle, Joanne (2001): 'The Dressed Body', Joanne Entwistle \& Elizabeth Wilson (eds): Body Dressing, Oxford \& New York: Berg.

Kawamura, Yuniya (2005): Fashion-ology, Oxford \& New York: Berg.

Moseley, Rachel (2005): Fashioning Film Stars: Dress, Culture, Identity, London: BFI.

Wilson, Elizabeth (2003): Adorned in Dreams: Fashion and Modernity, New Brunswick, New Jersey: Rutgers University Press. 